\title{
Collimation and surface counting in haematology
}

\author{
C. S. BOWRING AND H. I. GLASS \\ From the Department of Medical Physics, Hammersmith Hospital, London
}

SYNOPSIS The effect on the results obtained in surface counting investigations of using a dual detector counting system and multihole collimators has been investigated. The use of the additional detector results in smoother curves for the uptake of the radionuclide and the use of multihole collimators increases the discrimination of the counting system against the effects of radioactivity outside the region of interest. In a clinical trial to compare multihole collimation with conventional single hole collimation it was found that increased excess counts were obtained over the spleen with the multihole collimators in eight of ten cases.

Surface counting has been extensively used in haematological studies both in ferrokinetic investigations, using ${ }^{59} \mathrm{Fe}$ and ${ }^{52} \mathrm{Fe}$, and for the determination of sites of red cell destruction, using red blood cells labelled with ${ }^{51} \mathrm{Cr}$ (Jandl, Greenberg, Yonemoto, and Castle, 1956; Hughes-Jones and Szur, 1957; Lewis, Szur, and Dacie, 1960; Crook and Szur, 1960; Szur, 1970).

The apparatus used in such studies typically consists of a single scintillation detector with a single cylindrical hole collimator of length $60 \mathrm{~mm}$ and of internal diameter $50 \mathrm{~mm}$ (Szur, 1972). The detector is positioned over the organ to be counted, as close to the skin as possible, and is placed either in a vertical position or perpendicular to the body surface (lateral position). There are, however, several important sources of error in the technique, such as incorrect localization over the organ to be counted (especially the spleen) and difficulty in reproducing the counting geometry on successive occasions. These errors are also likely to be associated with the less than optimal design of the apparatus since the sensitivity of the equipment varies with the depth of the organ below the body surface and, in addition, if the field of view of the collimator is larger than optimal, this results in the detection of radioactivity from regions other than the region of interest.

Problems with localization of the spleen may be overcome by the prior administration of a small quantity (about $250 \mu \mathrm{Ci}$ ) of ${ }^{99} \mathrm{Tc}^{\mathrm{m}}$-labelled heatdamaged red blood cells and subsequent imaging or detection of the position of maximum count rate. In an attempt to reduce the magnitude of other sources of error, we have placed an additional scintillation Received for publication 18 June 1974. detector beneath the patient, vertically below the single detector normally used, and have fitted multihole collimators to restrict the field of view of the apparatus.

The greater uniformity of response which is obtained between the two detectors of a dual detector system may be expected to improve the reproducibility of the counting geometry and also to reduce the variation of the sensitivity with the depth of the region of interest beneath the skin. In addition, the smaller and more sharply defined field of view obtainable with multihole collimators may be expected to provide a result of greater significance since a larger proportion of the measured counts will then arise from the organ under investigation.

The results of using this additional detector and a restricted field of view are presented below.

\section{Technical Details}

METHOD AND EQUIPMENT

For ferrokinetic studies $5 \mu \mathrm{Ci}$ of either ${ }^{59} \mathrm{Fe}$ or ${ }^{52} \mathrm{Fe}$ was administered and the count rate was measured over the heart, liver, spleen, and sacrum. The first measurements were made approximately three minutes after the injection of the iron and were repeated every 20 minutes for the first three hours and then again at four and five hours after injection. For ${ }^{59} \mathrm{Fe}$ ferrokinetic studies, the count rates were also measured approximately three times each week for two or three weeks. For the determination of sites of red cell destruction autologous red blood cells labelled with $1 \cdot 2 \mu \mathrm{Ci}$ of ${ }^{51} \mathrm{Cr}$ per kilogram body weight were administered and the first measurements were made one hour after injection. The count rate 


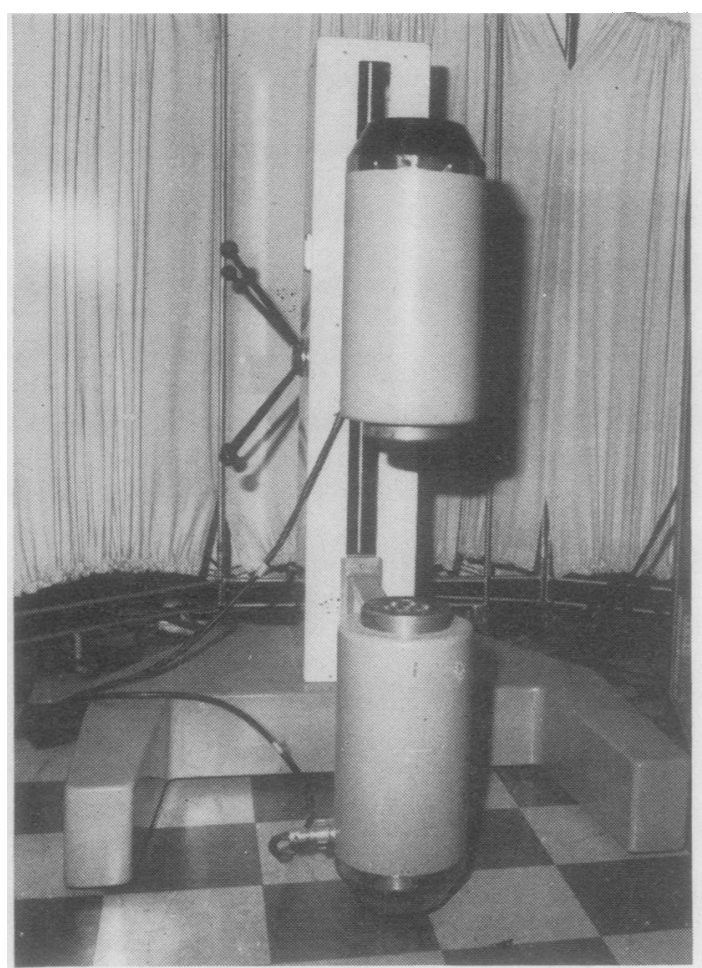

Fig 1a The stand and detectors

was measured over the heart, spleen, and liver, and the measurements were repeated three times a week for two to three weeks or until the count rate over the heart was less than half its initial value.

The equipment used to make the measurements consisted of two sodium iodide (thallium-activated) crystals $(90 \mathrm{~mm}$ diameter $\times 75 \mathrm{~mm}$ thickness) mounted vertically on the same stand, the separation between the two detectors being adjustable but usually of the order of 250 to $300 \mathrm{~mm}$ (fig 1). The pulses from each detector were taken independently through separate amplifiers and pulse height analy-

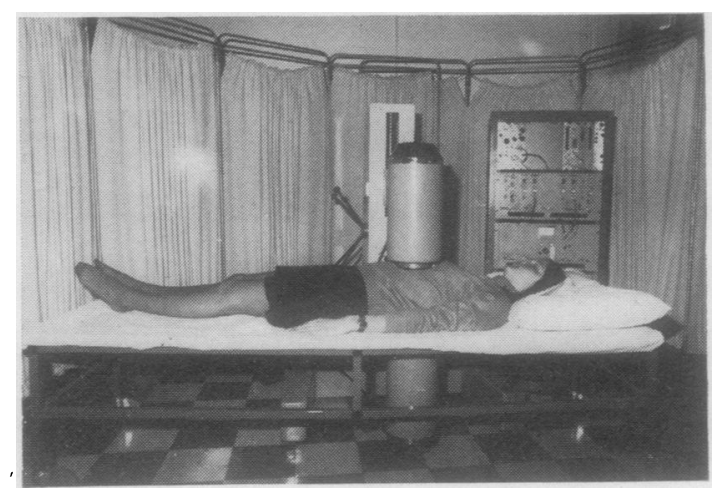

Fig 1b The complete counting system

sers to two scalers. This allowed the data from each detector to be analysed separately. Any difference in the results obtained using the data from the upper detector alone, and from the combination of the counts obtained from both detectors, could then be examined.

COLLIMATOR DESIGN

A collimator design study was made using a computer program (Simons, 1970). The criteria upon which the designs were evaluated were their fields of view, their point source sensitivities, and their plane source sensitivities. As a result of this study five pairs of collimators were constructed and their measured sensitivity and field of view are shown in table I. The point source sensitivities were measured in air with sources of ${ }^{51} \mathrm{Cr}$ and ${ }^{59} \mathrm{Fe} 150 \mathrm{~mm}$ from each collimator face, midway between the two detectors on the central axis of the collimators. (In table I these sensitivities are normalized to the value obtained for the collimators $70 \mathrm{~mm}$ long with a single hole $50 \mathrm{~mm}$ in diameter.) The plane source sensitivity was measured with ${ }^{51} \mathrm{Cr}$ only (window $260-380 \mathrm{KeV}$ ) at a distance of $150 \mathrm{~mm}$ from the collimator faces and the field of view was measured

\begin{tabular}{|c|c|c|c|c|c|c|c|c|c|}
\hline \multirow[t]{2}{*}{ Collimator Type } & \multirow{2}{*}{$\begin{array}{l}\text { Hole } \\
\text { Diameter } \\
(\mathrm{mm})\end{array}$} & \multirow{2}{*}{$\begin{array}{l}\text { Septum } \\
\text { Thickness } \\
(\mathrm{mm})\end{array}$} & \multirow[t]{2}{*}{$\begin{array}{l}\text { Length } \\
(\mathrm{mm})\end{array}$} & \multicolumn{2}{|c|}{$\begin{array}{l}\text { Diameter of Field of } \\
\text { View }{ }^{51} \mathrm{Cr}(\mathrm{mm})\end{array}$} & \multirow{2}{*}{$\begin{array}{l}\text { Diameter of } \\
\text { Field of View } \\
{ }^{59} \mathrm{Fe}(\mathrm{mm}) \\
(50 \% \mathrm{max})\end{array}$} & \multicolumn{2}{|c|}{$\begin{array}{l}\text { Normalized Point } \\
\text { Source Sensitivity }\end{array}$} & \multirow{2}{*}{$\begin{array}{l}{ }^{51} \text { Cr Plane Source } \\
\text { Sensitivity } \\
\left(c / s / \mu C i / \mathrm{cm}^{2}\right) \\
\text { (dual detector } \\
\text { system) }\end{array}$} \\
\hline & & & & $50 \% \max$ & $20 \% \max$ & & ${ }^{31} \mathrm{Cr}$ & ${ }^{50} \mathrm{Fe}$ & \\
\hline \multirow{5}{*}{$\begin{array}{l}\text { Single hole } \\
\text { Single hole } \\
\text { Single hole } \\
7 \text { parallel holes } \\
\text { (hexagonal array) } \\
19 \text { parallel holes } \\
\text { (hexagonal array) }\end{array}$} & 40 & - & 90 & 84 & 120 & 122 & 56 & 48 & 760 \\
\hline & 50 & - & 90 & 101 & 143 & 142 & 84 & 86 & - \\
\hline & 50 & - & 70 & 112 & 166 & 152 & 100 & 100 & 2900 \\
\hline & 22 & 6 & 90 & 65 & 98 & 119 & 61 & 71 & 640 \\
\hline & 16 & $1 \cdot 7$ & 90 & 61 & 89 & 144 & 45 & 67 & - \\
\hline
\end{tabular}

Table I Collimator characteristics 
by moving line sources of both ${ }^{51} \mathrm{Cr}$ and ${ }^{59} \mathrm{Fe}$ across the field of view at the same distance.

From table I it may be seen that the field of view is considerably reduced with both the multihole collimators for the $320 \mathrm{KeV}$ gamma ray emitted by ${ }^{51} \mathrm{Cr}$. This is especially noticeable in the measurements made at $20 \%$ of the maximum count rate which indicate the more sharply defined edge to the field of view obtained with the multihole collimators. For ${ }^{59} \mathrm{Fe}$, however, the field of view is only improved for the seven-hole collimator, presumably because the septa of the 19-hole collimator give insufficient absorption of the higher energy $\gamma$ rays of ${ }^{59} \mathrm{Fe}$. It can also be seen that the sensitivity of the multihole collimators is reduced for ${ }^{51} \mathrm{Cr}$ as compared with the single hole collimators. This is, however, not of great practical significance in a dual detector system since the count rate is effectively double that for the more conventional single detector system. We have found, when using two seven-hole collimators or one short $50-\mathrm{mm}$ diameter, single-hole collimator on the same patients, that essentially the same count rates are obtained with these two systems; but, as will be shown below, the counts obtained with the multihole collimators are likely to be more significant. In view of the fact that the performance of both designs of multihole collimator is similar for ${ }^{51} \mathrm{Cr}$ while for ${ }^{59} \mathrm{Fe}$ the seven-hole collimator is markedly better, the seven-hole collimators rather than the 19-hole collimators were used for the clinical trials. A diagram of the seven-hole collimator mounted in its protective casing is shown in figure 2.

The response of the double-headed system with the seven-hole collimators in position was measured by moving a ${ }^{51} \mathrm{Cr}$ line source across the field of view in air at various heights between the collimators separated by $300 \mathrm{~mm}$. These results are shown in table II, from which may be seen the very good uniformity of response with depth that is obtained with this dual collimator arrangement.

\section{DATA ANALYSIS}

The initial counts (corrected for background counts and physical decay) which were obtained for each organ were normalized to a value of 1000 and all

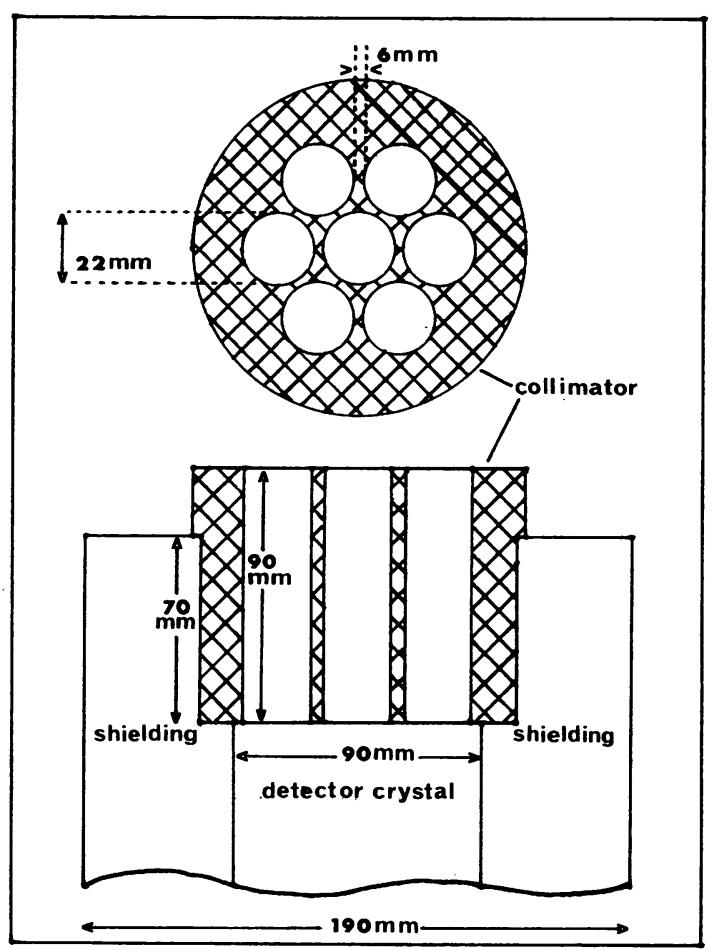

Fig $2 A$ diagram of the seven-hole collimator, enclosed in its shielding, which was selected for use in routine clinical investigations.

subsequent data were corrected using the same normalization factor. These normalized counts from each organ were fitted, using a least squares procedure, to a curve of the form $\mathrm{Y}=\mathrm{A}+\mathrm{Be}^{\mathrm{Ct}}$, by using a general curve fitting computer program (Marquardt, 1964). For each experimental point on the curve the modulus difference between the experimental value and the corresponding computed value was calculated and expressed as a percentage of the computed value. The average of these percentages for each curve was designated as the 'average percentage error in the uptake curve' and was used as an indication of the goodness of fit of the experimental points to the computed curve.

\begin{tabular}{|c|c|c|c|c|c|c|c|c|c|}
\hline \multirow{2}{*}{$\begin{array}{l}\text { Distance from Bottom } \\
\text { Face of Top Collimator } \\
(\mathrm{mm})\end{array}$} & \multirow{2}{*}{$\begin{array}{l}\text { Distance from Top } \\
\text { Face of Bottom } \\
\text { Collimator }(\mathrm{mm})\end{array}$} & \multicolumn{8}{|c|}{ Diameter of Field of View ( $\mathrm{mm})$} \\
\hline & & $90 \%$ & $80 \%$ & $70 \%$ & $60 \%$ & $50 \%$ & $40 \%$ & $30 \%$ & $20 \%$ \\
\hline $\begin{array}{r}200 \\
175 \\
150 \\
125 \\
100 \\
75\end{array}$ & $\begin{array}{l}100 \\
125 \\
150 \\
175 \\
200 \\
225\end{array}$ & $\begin{array}{l}32 \\
28 \\
27 \\
29 \\
30 \\
32\end{array}$ & $\begin{array}{l}45 \\
40 \\
40 \\
41 \\
41 \\
41\end{array}$ & $\begin{array}{l}53 \\
51 \\
50 \\
49 \\
50 \\
49\end{array}$ & $\begin{array}{l}61 \\
59 \\
58 \\
58 \\
58 \\
58\end{array}$ & $\begin{array}{l}67 \\
66 \\
65 \\
66 \\
66 \\
66\end{array}$ & $\begin{array}{l}74 \\
76 \\
76 \\
76 \\
75 \\
74\end{array}$ & $\begin{array}{l}84 \\
84 \\
85 \\
85 \\
84 \\
83\end{array}$ & $\begin{array}{l}96 \\
95 \\
95 \\
96 \\
95 \\
91\end{array}$ \\
\hline
\end{tabular}

Table II Response of system with two seven-hole collimators separated by $300 \mathrm{~mm}\left({ }^{51} \mathrm{Cr}\right)$ 

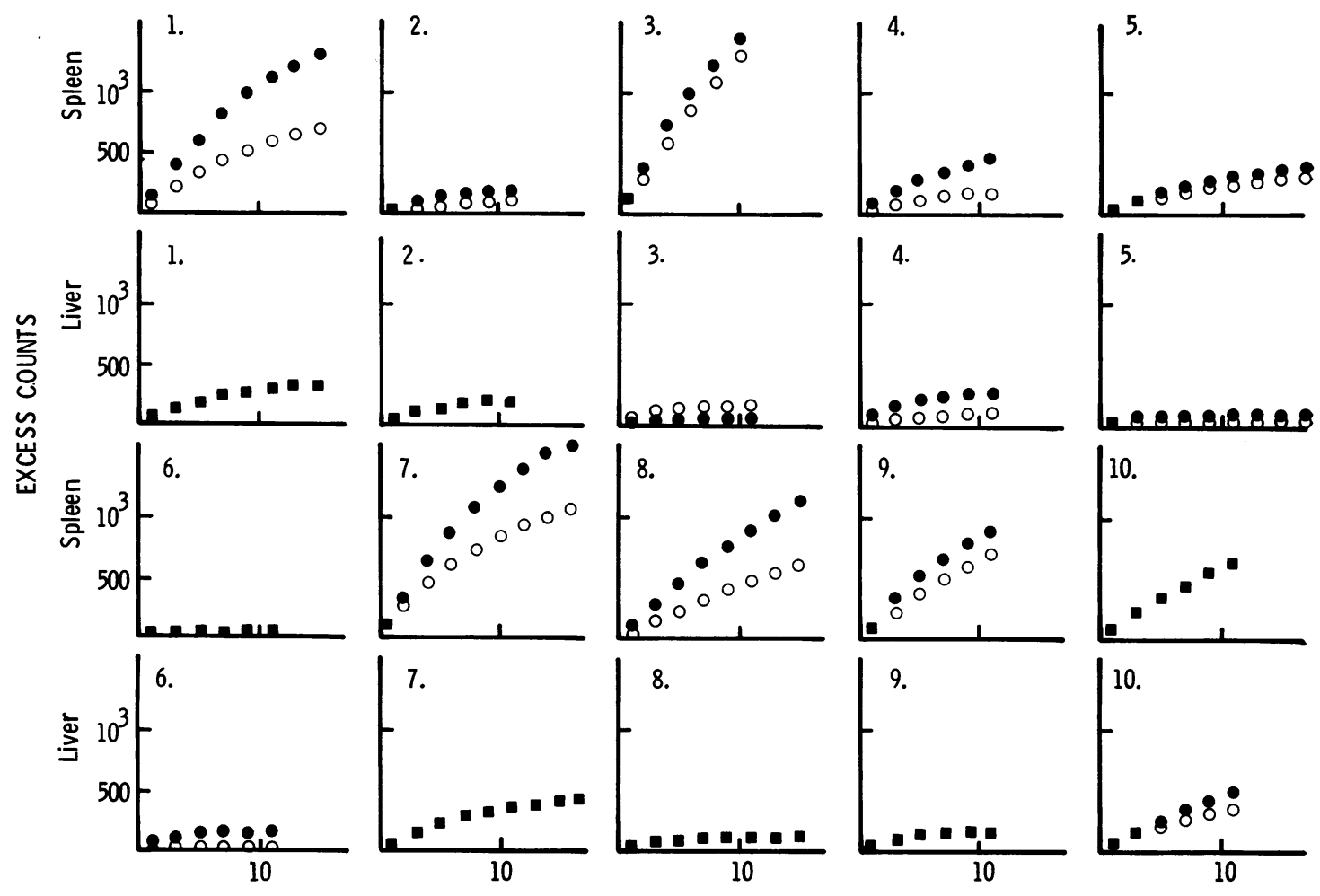

TIME (days)

Fig 3 The excess counts obtained over the spleen and liver in a series of 10 patients undergoing surface counting with ${ }^{51}$ Cr-labelled red blood cells. results obtained with the seven-hole collimators, $\bigcirc$ results obtained with the singlehole collimators, $\square$ identical results.

The excess counts (Lewis et al, 1960) obtained over the spleen and liver which are plotted in fig 3 (see results section) are the normalized ${ }^{51} \mathrm{Cr}$ counts obtained over the spleen and liver in excess of the normalized heart count for the same day. These provide an index of red cell destruction occurring in the spleen and liver.

\section{Results}

The results are presented in two sections. The first deals with the effect on the data of the use of the additional lower detector, and the second with the results obtained when using collimators of different designs.

THE EFFECT OF THE ADDITIONAL LOWER DETECTOR

In order to compare the results obtained from a single detector with those obtained with dual detectors it was assumed that the scatter of the data as indicated by the deviations of the experimental points from the smooth (computed) functions were mainly caused by experimental error. A total of 143 pairs of uptake curves were compared by the use of the 'average percentage error in the uptake curve' (see section on data analysis), and it was found that when using the additional data from the lower detector the average scatter of the measured points from the computer fit was reduced by $15 \%$. This improvement was statistically significant $(P<0.001)$. The same improvement was also found for the combined counts irrespective of whether the geometric or arithmetic mean was used to combine the counts. The measurements were made using each of the different sets of collimators and it was found that the improvement was independent of the particular collimator used. It is therefore suggested that this reduced scatter of the data results primarily from the reduced variation of the sensitivity with the depth of the organ which is obtained with a twodetector system. 


\begin{tabular}{|c|c|c|}
\hline Collimators & Radioisotope & Average Error \pm Standard Deviation \\
\hline $\begin{array}{l}7 \text { hole } \times 90 \mathrm{~mm} \text { depth } \\
40 \mathrm{~mm} \text { diam } \times 90 \mathrm{~mm} \text { depth } \\
50 \mathrm{~mm} \text { diam } \times 70 \mathrm{~mm} \text { depth } \\
7 \mathrm{hole} \times 90 \mathrm{~mm} \text { depth } \\
40 \mathrm{~mm} \text { diam } \times 90 \mathrm{~mm} \text { depth } \\
50 \mathrm{~mm} \text { diam } \times 70 \mathrm{~mm} \text { depth }\end{array}$ & $\begin{array}{l}{ }^{59} \mathrm{Fe} \\
{ }^{50} \mathrm{Fe} \\
{ }^{59} \mathrm{Fe} \\
{ }^{51} \mathrm{Cr} \\
{ }^{51} \mathrm{Cr} \\
{ }^{51} \mathrm{Cr}\end{array}$ & $\begin{array}{l}5 \cdot 1 \pm 1 \cdot 7 \\
6 \cdot 2 \pm 1 \cdot 0 \\
5 \cdot 8 \pm 1 \cdot 8 \\
7 \cdot 2 \pm 2 \cdot 0 \\
8 \cdot 4 \pm 2 \cdot 2 \\
7 \cdot 7 \pm 2 \cdot 2\end{array}$ \\
\hline
\end{tabular}

Table III A comparison of the values obtained for the 'average percentage error in the uptake curve' in a series of 28 patients

THE EFFECT OF INCREASED COLLIMATION In order to investigate the effect of using increased collimation the results obtained in a clinical trial using three different sets of collimators in the dual detector arrangement were compared. The collimators used were the single-hole collimators of length $90 \mathrm{~mm}$ and internal diameter $40 \mathrm{~mm}$, the single-hole collimators of length $70 \mathrm{~mm}$ and internal diameter $50 \mathrm{~mm}$, and the seven-hole collimators.

The problem of determining experimentally whether finer collimation is more useful clinically is not straightforward since it may be expected that collimators with a large field of view will provide an equally smooth uptake curve provided repositioning errors are similar in both cases. Because of this it was decided initially to compare only the values for the 'average percentage errors in the uptake curves' obtained for each radioisotope and collimator, and these results are shown in table III. From table III it may be concluded that, within the errors in the results, the seven-hole collimators produced uptake curves at least as smooth as those obtained with the coarser resolution collimators.

In order to attempt to quantitate the expected improvement in the results obtained with the sevenhole collimators, a limited trial was performed with 10 patients suffering from a wide variety of haematological disorders who were undergoing ${ }^{51} \mathrm{Cr}$ surface counting for investigation of the sites of red cell destruction. In this trial the patients were counted first with the pair of $50 \mathrm{~mm}$ diameter by $70 \mathrm{~mm}$ long single-hole collimators and then, immediately after, with the pair of seven-hole collimators. The 'excess counts' over the spleen and liver (Lewis et al, 1960) obtained on each patient with each set of collimators were compared. These are shown in fig 3, from which it can be seen that the seven-hole collimators gave higher excess counts over the spleen in eight of the 10 cases with two results being identical, whereas in the case of the liver higher excess counts were obtained in only four cases with identical curves being obtained in five cases. This is not unexpected since the spleen is generally much smaller than the liver; hence when counting over the spleen with the collimators with a large field of view more counts will be recorded which do not originate from splenic tissue than will be recorded from non-hepatic tissue when counting over the liver. Therefore, the ratio of 'splenic counts' to 'other tissue counts' obtained over the spleen may be expected to be smaller for collimators with a large field of view, as our results demonstrate.

It is also of interest to note the following points from figure 3. In cases 1 (Hodgkin's disease), 7 (aplastic anaemia), and 8 (thalassaemia), the rate of accumulation of excess counts measured over the spleen by the seven-hole collimators is greater than that measured with the single-hole collimators. In addition the number of 'excess counts' is much greater. In case 3 (haemoglobinopathy Köln), where there are more excess counts over the liver recorded with the single-hole collimators, it is probable that these are in fact scattered counts from the spleen since no excess counts would be expected over the liver in this patient. In case 6 (haemolytic anaemia), the patient was a 14-year-old boy who had previously had a splenectomy and hence any accumulation would be expected to occur in the liver as is shown by the results obtained with the seven-hole collimators.

It should be stressed that the previously reported upper limit of ${ }^{51} \mathrm{Cr}$ accumulation in the spleen in normal subjects in terms of excess counts of 300-350 (Szur, 1972) refers to a different detector counting geometry, and was obtained with a single detector in the lateral position. Since this arrangement would have included a contribution to the total count from the liver and possibly the heart while counting the spleen, the results obtained with the dual detector system must be interpreted with care until a new normal upper limit is established or the previous figure is confirmed. In this respect the result obtained over the spleen in case 4 (aplastic anaemia) is of particular interest, since with the single-hole detectors an excess spleen count of 250 is observed whilst the multihole detector system yields a figure of 450 .

\section{Conclusions}

It has been shown that the addition of a second 
lower detector to the surface counting apparatus improves the uniformity of the response of the system with depth and that this results in reduced scatter of the data in the uptake curve. It has also been shown that by using multihole collimators the field of view of the counting system can be reduced and more clearly delineated. This increases the significance of the uptake curves, since a larger proportion of the recorded counts then originate from the region of interest and a smaller proportion from the surrounding tissue and other organs. Although these improvements apply equally to surface counting with either iron or chromium they are of particular importance in ${ }^{51} \mathrm{Cr}$ studies in which a quantiative measurement of the splenic red cell destruction is being made (Szur et al, 1968; Williams, Szur, Glass, Lewis, Pettit, and Ahuja, 1974), when it is important that the number of excess counts shall be directly related to the removal of red cells by the spleen. By the use of dual multiple parallel hole collimators, improved discrimination against the effects of radioactivity outside the region of interest is achieved with no loss of sensitivity to the counts originating from within the region of interest as compared with the conventional single detector single-hole collimator system.

We gratefully acknowledge the assistance of clinical colleagues with this difficult and protracted study, in particular, Dr S. Bentley, Dr J. Ford, Dr P. Grammaticos, and Dr A. Ferrant. We also wish to thank Dr L. Szur and Dr S. M. Lewis for helpful comments and continuous encouragement.

\section{References}

Crook, A., and Szur, L. (1960). A simple method for the in vivo discrimination of chromium 51 and Iron 59. Brit. J. Radiol., 33, 447-450.

Hughes Jones, N. C., and Szur, L. (1957). Determination of the sites of red-cell destruction using ${ }^{51} \mathrm{Cr}$-labelled cells. Brit. J. Haemat., 3, 320-331.

Jandl, J. H., Greenberg, M. S., Yonemoto, R. H., and Castle, W. B. (1956). Clinical determination of the sites of red cell sequestration in hemolytic anemias. J. clin. Invest., 35, 842-867.

Lewis, S. M., Szur, L., and Dacie, J. V. (1960). The pattern of erythrocyte destruction in haemolytic anaemia, as studied with radioactive chromium. Brit. J. Haemat., 6, 122-139.

Marquardt, D. W. (1964). I.B.M. Share Programme, No. 3094.

Simons, H. A. B. (1970). A computer method for calculation of the point source response of a focusing collimator. Phys. Med. Biol., 15, 57-70.

Szur, L. (1972). In Blood Cell Survival Studies, (Radioisotopes in medical diagnosis). edited by E. H. Belcher and H. Vetter, pp, 342-382. Butterworths, London.

Szur, L., Glass, H. I., Lewis, S. M., Grammaticos, P., and de Garreta, A. C. (1968). Quantitative estimation of the red-cell uptake in the spleen using ${ }^{81} \mathrm{Rb}$ and ${ }^{51} \mathrm{Cr}$-labelled red cells. Brit. J. Radiol., 41, 819-826.

Szur, L. (1970). Surface counting in the assessment of sites of red cell destruction. Brit. J. Haemat., 18, 591-595.

Williams, E. D., Szur, L., Glass, H. I., Lewis, S. M., Pettit, J. E., Ahuja, S. (1974). Measurement of red cell destruction in the spleen. J. Lab. clin. Med., 84, 134-146. 